\title{
CIF Gold Medal Winners
}

\section{Rodney Smith, Maritime Forest Ranger School}

The recipient of the CIF/IFC Gold Medal at the recent Maritime Forest Ranger School Graduation Exercise was Rodney Smith of Fall River, Nova Scotia.

Rodney came to the Maritime Forest Ranger School as a single student ( 26 years of age) with a previous academic background in Resource Management (diploma from Holland College) and three years of Anthropology at the University of Prince Edward Island. Rodney previously worked as a Park Attendant with the Department of Natural Resources in Nova Scotia. For his summer practicum, Rodney was employed by the Maritime Forest Ranger School as a timber cruiser. While at our residential school he demonstrated very high standards in both field and class aspects of his studies, graduating with honours having the highest academic standing in his class.

Rodney also displayed strong interpersonal, communications and leadership skills to our staff and among his colleagues. He was very active in student affairs and served as treasurer on the Student Council.

It is our strong belief that Rodney will serve the forestry community extremely well in whatever capacity he can.

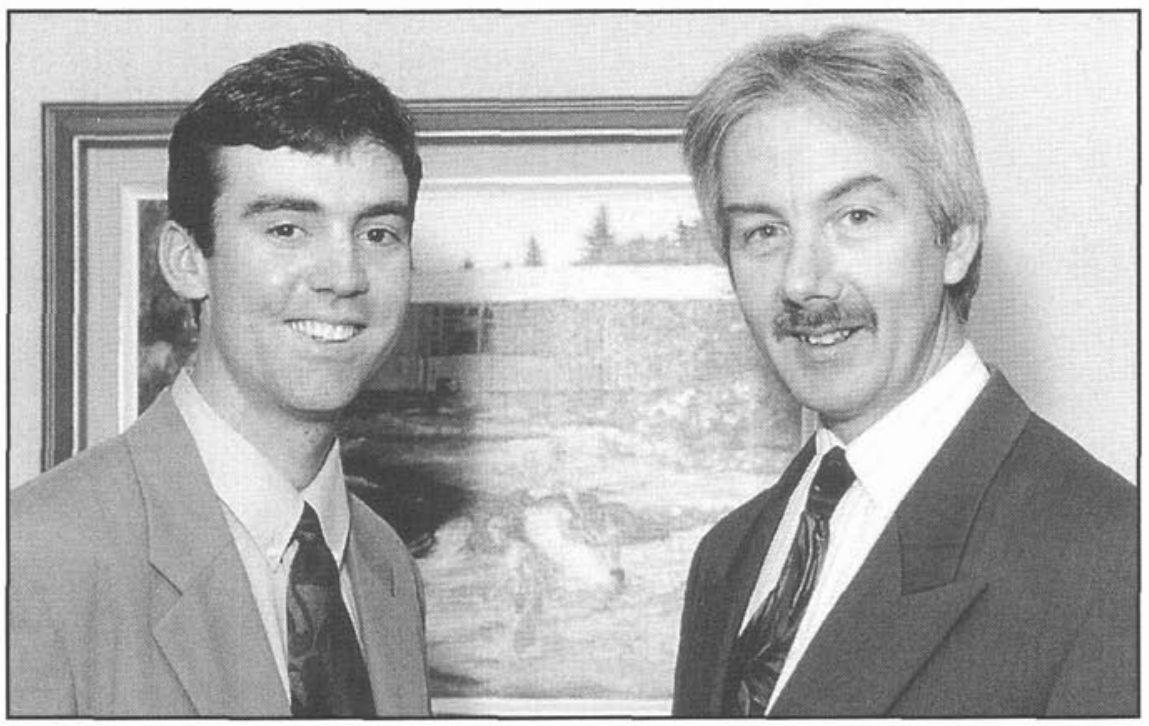

Rodney Smith (left) receives Gold Medal from Dave MacLean, Chair, Maritime Section.

\section{Sheryl Derko, Alberta Vocational College}

Sheryl Derko is our recipient for the CIF/IFC Gold Medal Award in the Forest Technician Program at the Alberta Vocational College, Lac La Biche.

Sheryl is a local lady, married with two children who decided on a career in forestry. Besides running her busy family life, Sheryl is very active in program functions and is always willing to give a helping hand to other students, whether it be with academic studies or personal tasks. Sheryl has excellent study and work habits along with a great attendance record. Her marks in the program are in the mid 80s. She also gives an honest effort in all of our field activities. All the staff of the Forest Technician Program acknowledge Sheryl as the deserving participant for the reward.

Continued on p. 251

\section{The Executive Director Reports, continued}

1948 - Suggested that all forestry undergraduates be taught sufficient biology to enable them to appreciate wildlife as a product of the forest; and that additional facilities be made available in universities for training in the field of wildlife.

1951 - Canadian Society of Forest Engineers officially renamed Canadian Institute of Forestry

1959 - Suggested that ways and means be developed for restocking cut-over lands and that the CIF urge government and industry to take appropriate cooperative action.

1964 - Recommended that the Federal Government be urged not to opt out of shared-cost forestry agreements, that the Federal Government's contribution to forestry be commensurate with tax rev- enues derived from the forests, and that a Forest Ministers' Conference be held as soon as possible to develop a new formula for forestry agreement.

1967 - Undertook the presenting of silver rings to undergraduates from Canadian forestry programs.

1975 - Recommended that the appropriate departments of the Federal and Provincial Governments of Canada provide action necessary to preserve endangered species and their associate natural habitat.

1989 - Urged the Canadian Council of Resource and Environment Ministers (CCREM) and the Canadian Council of Forest Ministers (CCFM) to petition the United Nations to establish a followup to the Brundtland Commission for the development of world protocols for dealing with environmental problems and of methods to measure and monitor the causes and the effects of identified problems as well as their results of corrective actions.

1993 - CIF/IFC supports the National Forest Strategy, and undertakes to support the establishment of RPFs in provinces without RPF associations.

1997 - Newfoundland CIF section establishes an RPF program in Newfoundland, Nova Scotia and Newfoundland sections technical sessions focus on their provincial wood supply situation.

1998 - Investigated through a task force a recognition program for a forest technician / forest technologists, supported and participated in the 1998 National Forest Congress. Manitoba section hosts a meeting to explore the establishment of RPFs in Manitoba. 


\section{Stephen C. Zoltai, BScF}

It is with deep regret that I report the passing of Stephen C. Zoltai on December 15,1997 . Steve Zoltai was an outstanding Canadian scientist who recently won the CIF Canadian Forestry Scientific Achievement Award. He was born in Hungary and educated in Austria and Canada (BSc.F., U of Toronto). His entire working career was spent in Canada, first with the Ontario Department of Lands and Forests, Research Branch (1957-1965) and then with the Canadian Forest Service or its predecessors (1965-present). He was a senior research scientist at the Northern Forestry Centre,

Steve developed knowledge in the field of forest and non-forest land classification and peatland ecology, contributing over 100 papers to the primary scientific literature, writing book chapters, developing thematic maps, contributing to scientific and learned societies both with papers and serving on technical committees. His actions and contributions to Canadian and northern plant ecology serve as a role model for young scientists in Canada. in Edmonton, Alberta.

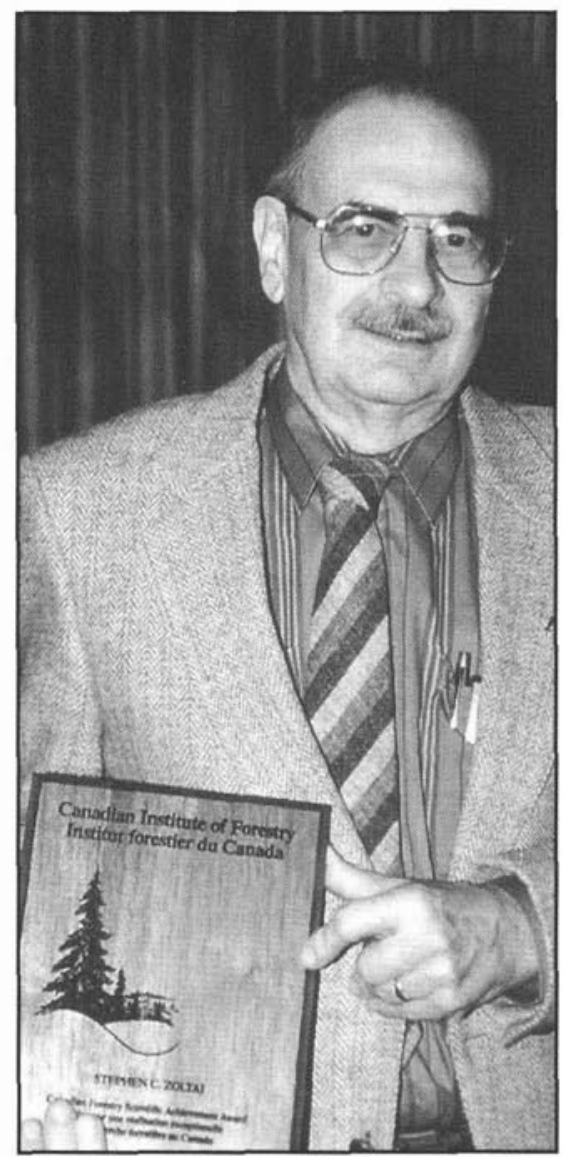

\section{Gold Medal Winners}

\section{Continued from p. 250}

James Webb, British Columbia Institute of Technology

James Webb is a second year Forestry student who is currently enrolled in the fourth of four terms required for the completion of a diploma in Forestry. Jim was tied with one other person for the highest GPA averaged over the last three terms. The total number of students currently enrolled in the second year of this Forestry program is just over 100 . Last term, Jim received marks in the nineties for his Forestry Technical Project course mark. His project, which is still in progress, involves an analysis of bias when using forest inventory sampling techniques.

Jim gets along exceptionally well with fellow students. He has been involved in the Student Leader Program and his experience with staff training and develop-

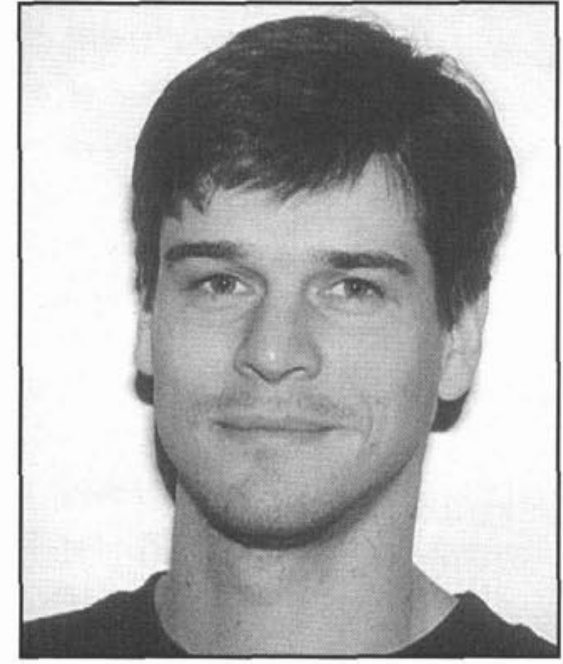

ment before he came to BCIT show through when he helps other students, either individually or in study groups. He is also involved in providing kayaking lessons on weekends.
He made many significant contributions to our understanding of boreal and arctic ecology through his work on forest land classification in Ontario, Manitoba, and the Northwest Territories. His greatest contributions came from his studies of boreal wetland ecosystems. He advanced our knowledge of how peatlands form and develop as well as the ecological relationships between vegetation-soilpermafrost within the Arctic and sub-arctic regions of western Canada. He conducted extensive research into the dynamics of peatland formation and the environmental impacts of resource development on permafrost areas. In recent years Steve's research efforts were directed toward the effect of climate change on forests and peatland dynamics.

Steve served the field of plant ecology well by contributing to the educating and training of competent biologists and researchers. He was an honorary professor at the University of Manitoba and an adjunct professor at the University of Alberta. He served on thesis committees of graduate students at the University of Alberta and the University of Ottawa. $\mathrm{He}$ also served with several scientific journals as an associate and guest editor.

Steve had an impressive international reputation. He collaborated with scientists from other boreal forest countries in addition to his colleagues in Canada. He served on several international scientific societies' working groups. Steve was invited and participated on the United Nations Human Resources Committee's team that examined the environmental impact of the oil pipeline spills in northern Russia.

Steve was the recipient of several awards for outstanding achievement in his field. He has received the Queen Elizabeth II Silver Anniversary Medal, Environment Canada's Merit Award, and most recently he was made a Fellow of the Royal Canadian Geographic Society.

Steve has made many outstanding contributions to forestry through his research in forest and plant ecology and in the area of environmental impacts in the Arctic and sub-arctic; his insight and efforts in these areas will be missed.

Steve is survived by his wife, Elizabeth, and children Stephen, Eve, Sue, Sandra, Julie and numerous grandchildren.

Ken Mallet, Rocky Mountain Section Continued on p. 252 